\title{
Carbon Footprint of ADU Students: Reasons and Solutions
}

\author{
Nida Qafisheh ${ }^{1}$, Makhtar Sarr ${ }^{1}$, Umm Amara Hussain ${ }^{1} \&$ Shikha Awadh $^{1}$ \\ ${ }^{1}$ Department of Applied Sciences, Abu Dhabi University, Abu Dhabi, UAE \\ Correspondence: Nida Qafisheh, Department of Applied Sciences, Abu Dhabi University, Abu Dhabi, UAE. \\ E-mail: nida.qafisheh@adu.ac.ae
}

\author{
Received: February 14, 2017 Accepted: March 13, 2017 Online Published: March 31, 2017 \\ doi:10.5539/ep.v6n1p27 \\ URL: https://doi.org/10.5539/ep.v6n1p27
}

\begin{abstract}
The objective of the study was to calculate the carbon footprint of ADU students, studying environmental sciences and environmental health \& safety and compared it with the average carbon footprint of UAE. Students' activity, which contributed to the highest emissions of carbon dioxide per year, has been determined. The carbon footprints were calculated using the online carbon footprint calculator, which estimated the $\mathrm{CO}_{2}$ emissions of each student. The method resulted from different activities like consumption of gas and electricity, transportation, flights, food as well as other different activities are associated with individual's life style. The average carbon footprint of Environmental ADU students after decreasing their emissions was 12.22 tons $\mathrm{CO}_{2}$ /year, which was $68 \%$, less than the average carbon footprint of UAE (37.8 tons/year). The public transportation, driving friendly cars, eating locally and living in a simply sustainable life style are great solutions to reduce an individual carbon footprint.
\end{abstract}

Keywords: carbon footprint, climate change, greenhouse gases, sustainability

\section{Introduction}

The term "carbon foot print" has become immensely common over the last few years, and is now prevalent, especially in media. Carbon calculations are in demand because the global climatic condition has been affected negatively due to the production of large volumes of greenhouse gases. Several methodologies have been projected to deliver approximations, extending from basic online calculator to sophisticated lifecycle examination or input/output based approaches (Terry, 2015). The goal of the study was to estimate and analyze the carbon foot print of ADU students and to compare it with UAE, World and industrial countries' carbon foot print. The study has intended to increase the awareness level of individuals about the personal footprints and the importance of using carbon footprint calculators. Additionally, it has provided awareness regarding environment; and by doing so, the effects would be reversed. In such way, the role of government in increasing awareness about the problem would be enhanced.

Carbon footprint is the total amount of greenhouse gases, produced per capita expressed in equivalent tons of carbon dioxide/year. Carbon foot print is the total quantity of greenhouse gases emitted directly and indirectly into the atmosphere. Carbon dioxide $\left(\mathrm{CO}_{2}\right)$ emission is usually expressed in tons per year. For instance, the burning of petrol usually generates a definite amount of $\mathrm{CO}_{2}$ depending on its gas ingestion and distance. Carbon dioxide gas is generated when an individual heats his/her home with oil, gas or coal. A certain amount of greenhouse gas is emitted as a result of cooled or warmed house with electricity during winter or summer respectively. The buying of food and goods would also contribute to the global warming, for energy utilized to manufacture them (Print, 2013).

In recent years, a huge amount of carbon emission has been reported from food transportation among different countries using air routes (Konicyzni, 2013). The method has focused on the transportation of food by minimizing the hazards for reducing safety concerns. The analysis of farm to fork process confirmed that the highest environmental risks are associated with raw foods like meat, fish, processed food items, poultry, etc. (Konicyzni, 2013). A study in 2007 revealed that 200 metric tons of food are transported every year globally, which includes $35 \%$ by land transportation, $60 \%$ by sea transportation and just $5 \%$ by air routes. For the purpose of transportation, airplanes are extremely expensive and emit tons of carbon dioxide (Bendickson, 2007). It has been estimated that the constituents of the global warming gases in European countries include nitrous oxide 54 percent; carbon dioxide 45 percent, volatile organic compounds excluding methane 23 percent and some other 
gases contributes 20 percent. The source of these gases is none other than transportation. The excessive amount of greenhouse gases will cause harm to both humans and the natural environment (Badyada, 2010). An airplane, loaded with imported or exported food, can burn thousand pounds fuel. The airplanes and sea vessels use fuel from fossils and produce great amount of carbon emissions comparatively. In addition, huge trucks are needed to carry the goods from air bases to the sale markets, which release carbon dioxide into the environment. These global warming gases mainly include carbon dioxide and some methane. These gases are also termed as Kyoto gases after the signing of the contract of Kyoto protocol (Spooner, 2012).

The international Kyoto protocol includes the treaty for the products of meat and other food systems. Each an estimation done in United States food system utilizes 19 percent of the fossil energy every year in total. Seven percent out of 19 was used for the process of agriculture, seven percent for packaging and processing and about five percent for food preparation for consumers and distributions (Pimental, 2006). The burping of methane from cows also contributes to the natural environment, so the carbon emissions from dairy farm are about 73 percent (Anonymous, 2012). The decline in fuel consumption in the transportation system recycled along entire food chain phases is the most acute factor, which influences carbon emissions. The emission of carbon dioxide gases varies from 2.2 to $3.3 \mathrm{~kg}$ carbon dioxide per one $\mathrm{kg}$ of coal and gasoline (Konicyzni, 2013). Air, rail, truck and water are the four fundamental methods of package material transport in developed countries. Most of the shipping needs bulk transport like water barge, rail and transportation by trucks leads most logistic systems. The cheapest and flexible mode of transportation is by using transporting trucks for unpreserved foods (Akerley, 2010). The consumption of carbon emissions can be reduced if the old motors would be replaced by new vehicles, which are more energy efficient and consume less fuel (Conolly, 2008).

Reduction in carbon emissions can be contributed by every single private and governmental organization including schools, universities, businesses, industries, etc. It has been suggested that educational institutions are the major sources of carbon emissions along with factories and manufacturing industries. Calculating the carbon foot print of an educational institute can provoke the sense of obligation among students to minimize it accordingly. Such methods of greenhouse gas regulation will help to create sustainable schools and colleges. The carbon emission of a company can be measured on three different scopes including direct emissions, indirect emissions, and the out sourced emissions (Sivaram, 2015).

Carbon footprint is one of the main ecological impacts, which has gained much attention from government, media and public. It is one of the primary topics of any governmental agenda and also for the nations, which are trying best to reduce their carbon footprint of their consumers and products. Every industry has its own distinct modelling and assessment techniques, mitigation and allocation procedures for its carbon emission (Muthu, 2015). The industry-level benchmarks have been considered as the plans developed for the supply chain carbon maps to set a measure for the environmental sustainability of the product supply chains. The first step for the firms has been provided by the industry-level benchmark to manage the environmental performance and target along with the identification of high carbon emissions for the cross-sectional benchmarking (Acquaye et al., 2014). Presently, the companies are controlled in a carbon-constrained environment. Particularly, the automobile industry is under pressure to focus at its product carbon footprint. The management of downstream situations of the use of its inputs and products from upstream supplier is crucial for the development of carbon risk-mitigated supply chain management (Lee, 2011).

The use of energy continues to rise and discharges $\mathrm{CO}_{2}$ with it. Energy efficiency techniques have been implemented across sectors. Efficiency gains and use of energy per manufactured unit have fallen, specifically in relation to the processing manufactures. Work place, residential, service sectors, and leisure until now use huge amounts of energy and so produce heavy emissions of $\mathrm{CO}_{2}$ regardless of efficiency gains. Effective strategies applied in the processing industry for developing energy systems, specifically total site targeting, are used to locally incorporated energy sectors. The method demonstrated that it could be successfully applied to combine renewables into the source of energy mix and consequently decrease the carbon footprint of those locally integrated energy sectors (Integrating waste and renewable energy to reduce the carbon footprint of locally integrated energy sectors, 2008).

The study focused on calculating the carbon footprint of individuals since it is a major factor that contributes to climate change. The governments have identified limits of greenhouse gases emissions for the organizations, so the concern is with the individual carbon footprint. The major problem is that many people do not realize the risk of producing large quantities of carbon by their activities, and they do not know the right actions to minimize the carbon footprint. The techniques of calculating carbon footprint can lead to shrink personal carbon footprint. However, an individual has lower control over the share of government and national capital emissions. There should be an account for these kinds of emissions if the useful comparisons between international targets and 
own footprints are required (Carbon footprint, n.d.).

\section{Method}

The study has been accomplished by using various approaches including data collection regarding carbon foot print from research articles and data bases of ADU library. Literature review has been written using Ebesco, science direct and ProQuest databases. The carbon foot prints of Abu Dhabi University students' were recorded by collecting carbon foot print reports of each student, who calculated carbon foot print using online carbon footprint calculator during the period of Fall 2012-Fall 2015. Solutions to minimize the carbon footprint in respect of industrial countries is about 11 tons. Results of students' reports were analyzed to estimate the total emissions of carbon dioxide in tons per year. Carbon foot print calculator calculated carbon dioxide emissions, which resulted from different activities like household, road and air transportation, types of food consumed and other students' lifestyles. Statistical analysis was performed using StatCrunch software.

\section{Results}

\subsection{ADU Male Students}

Carbon dioxide emissions resulted from different activities of ADU male students were collected. Figure 1 below showed the males' average emissions of carbon dioxide in metric tons per year for each activity. The activities that have been considered in analysis are household, flight, road transport and secondary activities like the kind of food they consumed, recreational activities and so on. The figure showed that the average carbon foot print (Carbon total) of ADU male students is 18.89 tons of $\mathrm{CO}_{2} /$ year. Transportation on roads like using cars, buses or taxies produced the highest emissions of carbon dioxide (8.23 tons of $\mathrm{CO}_{2} /$ year) compared with other activities. It has been explained that most of the students own cars, some of them have more than one car so this increases the fuel consumption and consequently the emissions of carbon dioxide, in addition few students use public transportation.

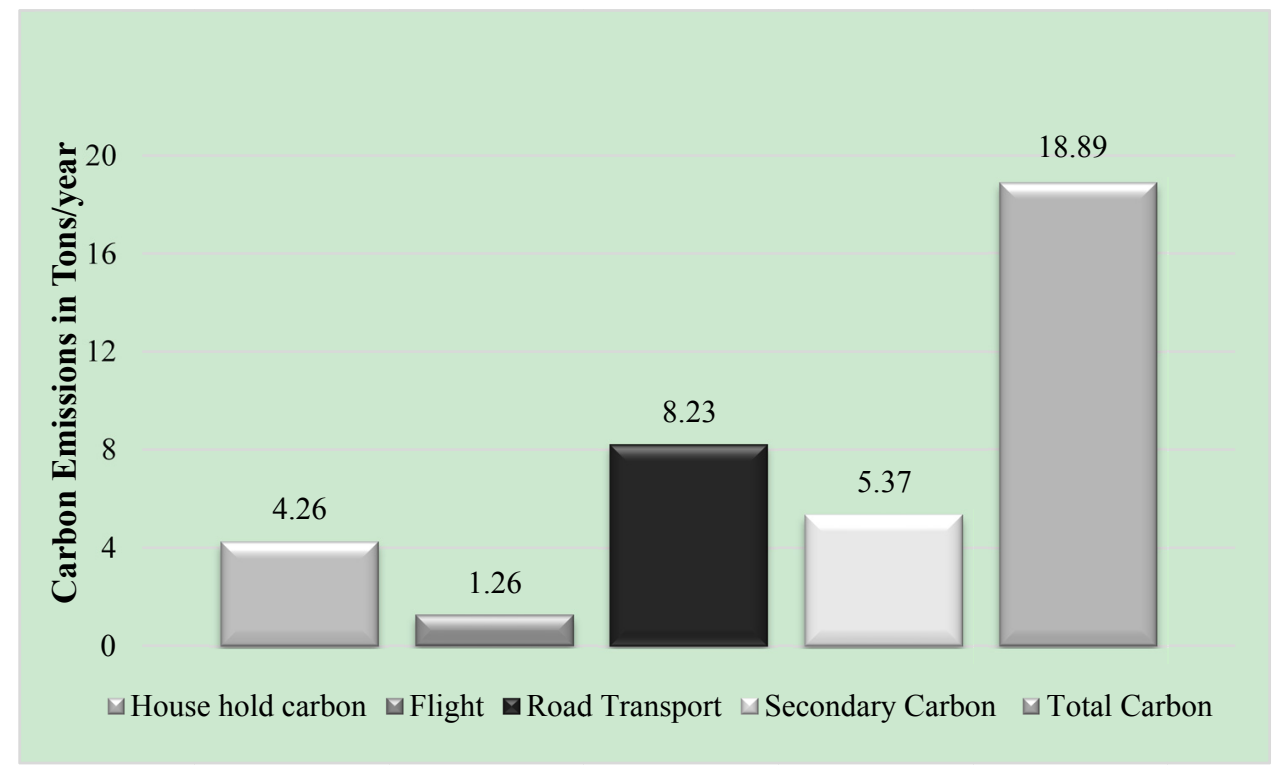

Figure 1. Average Carbon Footprint of male students

The second highest category was the secondary carbon, which is the amount of indirect discharges related to the manufacture and breakdown of all the services, products and food that a person or business consumes (Carbon footprint, 2010). It contributed with average of 5.37 metric tons of $\mathrm{CO}_{2}$. Household contributes by an average of 4.26 metric tons of $\mathrm{CO}_{2}$. Electricity has a huge impact on the climate because it plays a great role in increasing the carbon emissions. In addition, the continuous use of air conditioners due to hot weather increases the carbon dioxide emissions. The lowest average is for flight 1.26 metric tons of $\mathrm{CO}_{2}$. The reason behind this aspect is that all students did not travel, and most of them who travelled used the economic class, which releases less carbon dioxide compared in comparison to other classes due to less services (First class and Business class). This provided more services and more food and require more electricity, which means greater fuel consumption.

Figure 2 has described the average carbon footprints of ADU female students. It showed carbon emission from various activities as described previously for male students. The data was recorded by using carbon foot prints 
reports, which were completed by female students using the online carbon footprint calculator. The figure showed that the average carbon foot print (Total Carbon) of ADU female students is 19.32 tons of $\mathrm{CO}_{2} /$ year.

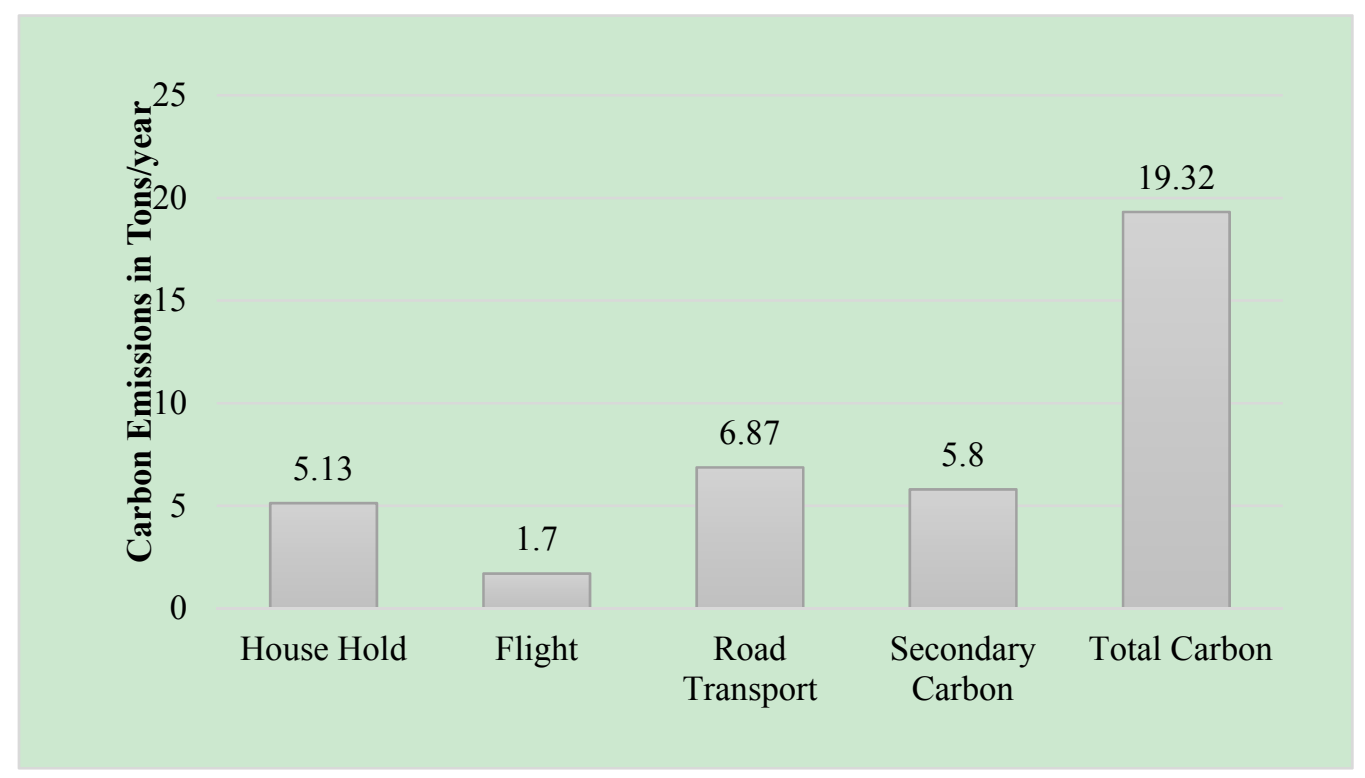

Figure 2. Average Carbon Footprint of female students

By comparing the average total carbon foot print of male vs. female students (18.89 vs. 19.3 tons/year), it has been figured out that female students have higher carbon footprint than male students; as the number of female students is higher in the applied science department compared to males, so average total turned out to be higher.

Transportation on roads produced the highest emissions (6.87 tons of $\mathrm{CO}_{2} /$ year). It has been observed with higher value as most of the students usually have their personal vehicles However, it is lesser than male students ( 8.23 tons/year) since male students travel for long distances as many of them live far away from the university. It has been observed that some of the female students live in ADU dorms and they usually use public transportation.

The second category was the emission resulted from secondary activities (5.8 tons $\mathrm{CO}_{2} /$ year). The secondary activities included the type of food an individual is consuming whether it is organic or processed. Similarly, the type of meat; if it is red or white. The result was higher than the male students (5.3 tons $\mathrm{CO}_{2} /$ year) as the female spend more on fashionable trends, mobiles and buy new furniture more often.

The average carbon emission from household activities was about 5.13 tons of $\mathrm{CO}_{2}$ /year. Household carbon emission resulted from different activities like consumption of water and electricity. The results have shown that the female carbon emissions were higher than males. This higher emission indicated that females spend more time in their houses compared to males. Many female students are housewives with kids; so, they use several electrical appliances for washing and cleaning etc.

The average emissions from flight was about 1.7 tons of $\mathrm{CO}_{2} /$ year which was the least category. It is higher than male students (1.2 tons of $\mathrm{CO}_{2} /$ year) as the females travel more than one flight per year and there are more female international students than male; in addition, many of them travel by business class.

\subsection{Average Carbon Footprint of All Students (Male \& Female)}

Figure 3 has illustrated the average carbon footprint of all the students combined regardless of their gender. The total average is 19.2 tons of $\mathrm{CO}_{2} /$ year and the averages for household, flight, transportation, and secondary are $4.8,1.5,7.4,5.7$ tons/year respectively. 


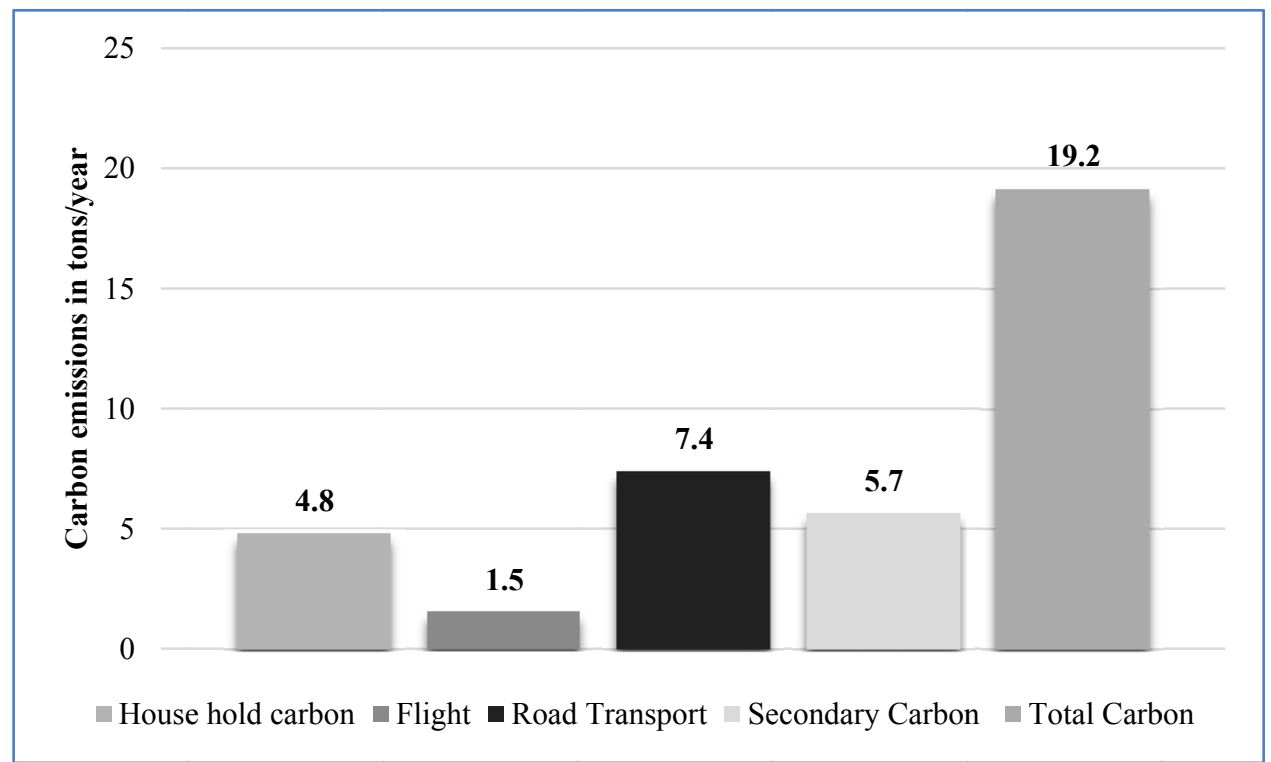

Figure 3. Average Carbon Footprint of all students

\subsection{Solutions for Carbon Footprint Reduction}

To reduce carbon footprint, students were asked to change their attitudes in their different activities and then to recalculate their new carbon footprint. The students were suggested to do the following:

\subsubsection{Reduce Carbon Footprint from Households}

- Try to make energy efficiency a main consideration, when buying air conditioner unit, furnace, refrigerator, or dishwasher.

- Switching off the lights, which are not in use. Change incandescent lights with compact fluorescent or the LED lights.

- Reduce dairy and/or meat consumption. Meat processing requires significant amounts of fossil fuels, which add carbon dioxide to the air.

- Maintain the cooling and heating systems as per manufacturer's instructions. Appropriate maintenance reduces the amount of power used.

- Reduce carbon footprint from flights.

- Increase the use of video-conferencing applications such as Skype or face time.

\subsubsection{Reduce Carbon Footprint from Transportation}

- Alternatives to driving: the usage of bicycle would be significant for avoiding carbon emission.

- Drive an electric or hybrid vehicle as high mileage cars do not indicate low $\mathrm{CO}_{2}$ emissions. The vehicles have an expected miles-per-gallon rating. Electrical vehicles produce zero $\mathrm{CO}_{2}$ if they are recharged with clean electricity.

- Increasing fuel efficiency with advanced technologies, design, and materials.

- Reduce travelling demand using urban planning to decrease the miles that individuals drive every day. (Sources of Greenhouse Gas Emissions, 2015).

\subsubsection{Reduce Secondary Carbon Footprint}

- The dietary habits must include local products and organic food, as research has anticipated that $13 \%$ of U.S. greenhouse gases arise from the transport and production of food. Transporting food needs petroleum-based fuels as well as many fertilizers, which are fossil fuel-based.

- Avoid bottled water or apply good quality water filtration systems. It requires 47 million gallons of fuel to manufacture the plastic water bottles used in the US annually.

- Avoid materialistic packaging in products. 
- Reduce the amount of power used to treat, heat, and pump water by washing vehicle less frequently

- Using climate-appropriate vegetation.

- Installing drip irrigation to ensure that plants get the necessary amount of water.

- Reduce, recycle and reuse. Research has estimated that $29 \%$ of U.S. by getting used products and recycling or reselling items, one must no longer use and dramatically decrease the carbon footprint from the "provision of products."

- Support clean energy resources for example solar, geothermal, wind, and properly designed hydroelectric as well as biomass energy projects.

\subsection{Carbon Footprint of ADU Students after Reducing their Emissions}

The students were asked to change their lifestyles to reduce carbon emissions and to calculate their expected carbon footprint again using carbon foot print calculator. They reduced their carbon footprint by using alternatives and changing or minimizing some activities like following urban plan and using public transportation to minimize the carbon emissions from transportation. The secondary carbon was reduced by minimizing the indirect discharges that are related to manufacturing and some services, avoiding useless packaging, not changing their devices after short period, having more organic food, fruits and vegetables in daily diets rather than having red meat more often, and many other alternative options recommended in section 3.4.

Reducing the amount of electricity used in households by turning off extra lights and air conditions when they are not in use, and following the triple (R) method: reduce, reuse, and recycle. They also tried to combine their trips to decrease the number of flights, and they choose to direct fly rather than transit or stop over. After making these changes to their life style the carbon footprint was reduced to 12.22 tons $\mathrm{CO}_{2} /$ year. If this value is compared with the previous carbon footprint 19.2 tons $\mathrm{CO}_{2} /$ year; it means that the students managed to reduce their emissions by $36.5 \%$.

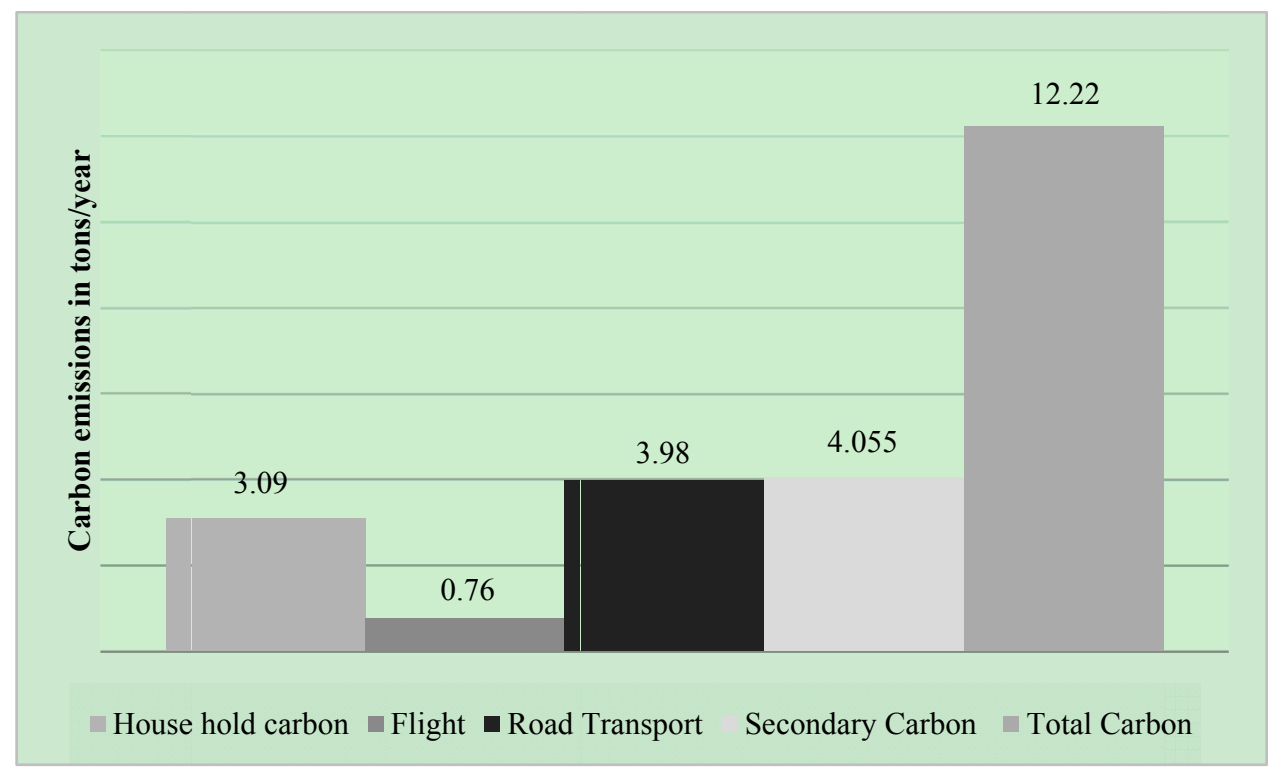

Figure 4. Average Carbon Footprint of all students after reduction

\subsection{Statistical Analysis}

Samples are dependent since the subjects are paired with respect to their total carbon footprints being measured before and after reduction of the emissions. Using Stat Crunch software, the outputs for the hypothesis testing at a significance level of 0.05 along with the $95 \%$ confidence interval has been displayed below in Tables $1 \& 2$ : 
Table 1. Hypothesis test results

\begin{tabular}{llllll}
\hline Difference & Sample Diff. & Std. Err. & DF & T-Stat & P-value \\
\hline TotCarBfr - TotCarAft & 6.5688889 & 1.6080251 & 71 & 4.0850661 & 0.0001
\end{tabular}

$\mu_{\mathrm{D}}=\mu_{1}-\mu_{2}$ : Mean of the difference between TotCarBfr and TotCarAft

$\mathrm{H}_{0}: \mu_{\mathrm{D}}=0$

$\mathrm{H}_{\mathrm{A}}: \mu_{\mathrm{D}} \neq 0$

Table $2.95 \%$ confidence interval results

\begin{tabular}{|c|c|c|c|c|c|c|}
\hline Difference & & Sample Diff. & Std. Err. & DF & L. Limit & U. Limit \\
\hline $\begin{array}{l}\text { TotCarBfr } \\
\text { TotCarAft }\end{array}$ & - & 6.5688889 & 1.6080251 & 71 & 3.3625779 & 9.7751999 \\
\hline
\end{tabular}

$\mu_{\mathrm{D}}=\mu_{1}-\mu_{2}$ : Mean of the difference between TotCarBfr and TotCarAft

Based on the outputs above, there is enough evidence to support the claim that subjects' measurements before and after have means that are significantly different at a significance level of 0.05 since the P-value is highly significant.

Table 3. Statistical Analysis of the results before and after reduction.

\begin{tabular}{lll}
\hline & Sample means & Sample standard deviations \\
\hline Before Reduction & 19.1 & 12.9 \\
After Reduction & 10.1 & 7.3 \\
\hline
\end{tabular}

Table 3 showed that both means and the standard deviation have been reduced before and after reduction of carbon emissions.

\subsection{Comparing the World, Industrial Nations, and UAE Average Carbon Footprint with ADU Students}

It has been stated that the global carbon footprint average is approximately 4 tons of carbon dioxide, the United Arab Emirates average is 37.8 tons per year, and average carbon foot print of all industrial countries is 11 tons per year. The result of ADU students is 12.22 tons of carbon dioxide after reducing the activities that emit large quantities of carbon dioxide. It is high comparing to the world's average carbon foot print, but it is close to the industrial countries. The positive sign of this study is that the students have much less result than UAE average (37.8), which is one of the highest worldwide. The students managed to reduce their carbon footprint $68 \%$ less than UAE average.

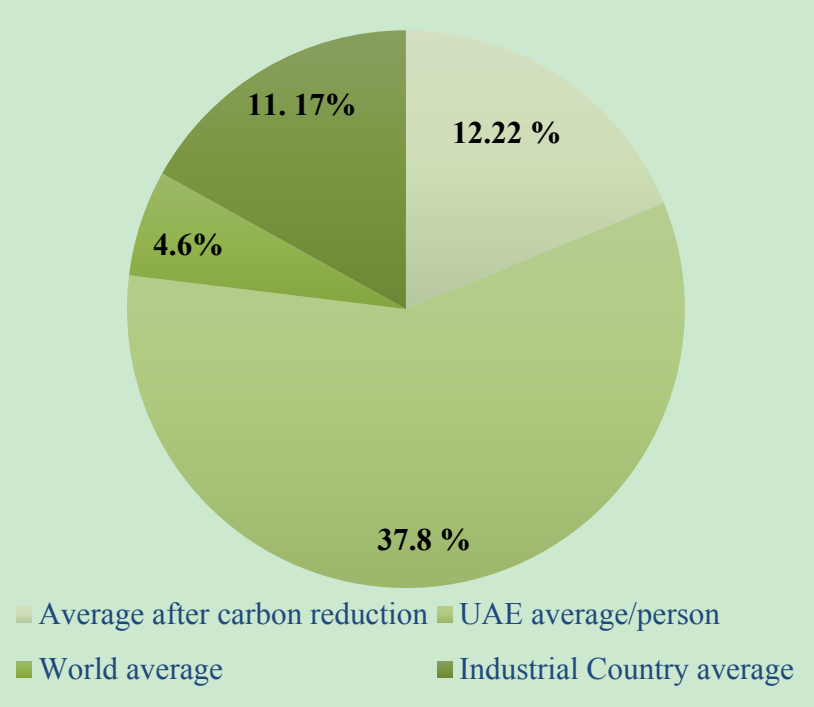

Figure 5. Carbon Emissions in tons/year. 


\section{Discussion}

The sum of greenhouse gas emissions linked with the processing, transporting, retailing and food production is the carbon footprint. The environmental impact of food is required to be associated with the concerns about the density of nutrition and health. GHG (Anthropogenic greenhouse gas) emissions are the main reason for the global change in climate, which can be considered as an urgent problem that various international organizations and countries are willing to resolve (Buendia et al., 2006). The concentration of atmospheric carbon dioxide $\left(\mathrm{CO}_{2}\right)$ has amplified from 279-397 ppm since 1800, which is mainly because of the fossil fuel combustion (Herzog, 2009). In terms of anthropogenic greenhouse gas, university-inclusive analysis also turns within a wide trend of operating, designing and in some cases adaptable low carbon communities and organization. These steps require different procedures for allocating emissions. Contrasting in some similar studies just by separating gross emission with the population size, these assigning must arbitrate responsibility for emission. This might bring the model to play a complex range of economic, social, accounting, ethical and even political questions. The all-purpose term used for the calculation of study was carbon footprints, which has attained currency broadly due to the advocacy organizations and to private sector interest. The carbon footprint is basically the sum of anthropogenic greenhouse gas emission that can be credited to an activity, organization and process. This notion depends highly on the specifications of the methods and scope. The scope assigns the boundaries of the system and maintains an order of responsibilities. It also comprises sequential limits in terms of the lifecycle phases and stages. This phase can comprise of production or upstream emissions, active stage emissions and the downstream emissions.

A study conducted by Brand et al. (2013) has hypothesized the carbon dioxide emissions from motorized travel to be linked with the household, individual and other environmental consequences. There are little but strong evidences present that contributes most to travel carbon dioxide and also the factors influencing business, computing and social travel carbon dioxide. The study has examined how and whether the socio-economic, demographic and other environmental and personal characteristics are related with the land based traveler transport and linked carbon dioxide emission. The participants reported their previous week activity and vehicle characteristics from which the carbon dioxide emissions were evaluated utilizing an adapted travel emissions profiling procedure. Linear and multivariate regression analysis has determined the characteristics that predicted higher carbon dioxide emissions. Carbon dioxide emissions from motorized travel were dispersed unequally with the top 5th of participants creating more than two fifth of the emissions. The overall carbon dioxide emission was dominated by car traveler, making up to ninety percent of the total. The powerful independent predictors of the carbon dioxide emissions were possessing only one car having a home-work distance of more than 10 kilometer. Tenure, income, and education were also a powerful uni-variable predictors of carbon dioxide emissions, but it was observed to be further back on the usual path than having a car. The results have helped to clarify the improvement of climate change mitigation strategies for the transportation sector. Targeting households and individuals with high car tenure, concentrating on offering reliable alternative to travelling by car and encouraging planning and other strategies as well. The reduced travelling distances might offer an efficient and equitable approach to meet carbon mitigation objectives.

A study conducted by Benjaafar \& Daskin, (2013) have applied simple and broadly used models and also illustrated how the concerns of carbon emission can be assimilated into the operative decision making in regards with the inventory, production and procurement management. The carbon footprints parameters were associated with the different decision variables. Conventional variables were also modified to enhance and support the decision making that accounts for the carbon footprints and cost. It has been examined that the values of the parameters and regulatory emission control policies parameters affects the emissions and costs. Models were used to study the degree to which the carbon lessening necessities can be evaluated by the operational judgements, as a substitute to invest in carbon reduction advancements. The models to explore the impact of collaboration have also been used among firms within the same supply chain on their carbon emission and costs. The study has addressed the incentives firms may encounter in seeking the cooperation. A series of views have been highlighted to show the significance of the operational methods in examining the effect of different administering strategies and in evaluating the advantages of investments in more effectual carbon technologies. The aim was not to provide an inclusive solution to any single problem, but to focus the types of problems that grows when the carbon footprints considerations are included in the supply chain management. The study has aimed to focus on the emerging investigation field in operations that is rich potentially with communal impact.

A study conducted by Li \& Rackes (2015) have applied a model of an Environmental Extended Input Output (EEIO) to evaluate the carbon footprint of the Norwegian University of Technology and Science (NTNU). The findings have shown that the carbon footprint of the considered university was significant with a mean 
contribution of 4.6 tons each student. Particularly, the large amount purchase of consumables and equipment for scientific use has also been found an important contributor. Per department carbon footprints were also evaluated by this study, which enabled the standardized structure of the financial system of accounting applied or used by the university. The results have shown large variations in the carbon footprints of several faculties. Humanities and social sciences have a significantly lesser carbon footprints per student as compared to the Engineering, Natural Science and Medicine faculty. The chief contributor to the university was assigned to the property department for the use of energy and other infrastructure related practices. The carbon footprints structures of the faculties or department has shown a large difference which refers that different modification strategies are required.

The mitigation of GHG has generally emphasized on the sources of its emission, but has given little attention on the emission drivers. In most of the situations, the emission drivers could have been deemed as individual consumers; however, an individual consumer in a broader perspective may have slight control. Thus, at several scales the emission drivers need to be considered.

As the climate changes are high up on the political agenda, the calculations of carbon footprint were observed to be in strong demand. Despite the ubiquitous nature of carbon footprint, still no clear academic definition exists that has left in confusion that what specific units and measures should be used. Since several decades, the phenomenon regarding the carbon footprint has been used extensively; however, it was recognized differently in the form of global warming potential indicator (Finkbeiner, 2009). Thus, currently the carbon footprint is reviewed as hybrid, where its name has been derived from ecological footprint.

Little research was attempted in order to connect the impact of household and exploring the global environmental impacts of the emission of the greenhouse gas. In recent times, interest has been increased for studying the environmental impacts of globalization and international trade. Thus, carbon leakage is connected with the international trade consequences, which represents severe environmental problems. A study has provided an estimation for the average $\mathrm{CO}_{2}$ used in US to meet the household consumption, around $15 \%$ and $30 \%$, estimated to impact outside the US (Weber \& Matthews, 2008).

According to a study, some common processes enable the emission of greenhouse gas that subsequently provide benefits to humans in terms of producing new goods or services (Wiedmann et al., 2015). The study analyzed eight different categories as the source of emission of greenhouse gas. From all the categories, $72 \%$ of the greenhouse gas emission resulted from household consumption and 19\% was accounted from residence maintenance. Additionally, another study stated mobility as one of the category, which causes prominent GHG emission leading to environmental problems (Hertwich \& Peters, 2009). On the contrary, manufactured goods were also categorized as a separate category causing the emission of GHG entailing concerns for carbon leakage that needs sheer attention to be addressed (Peters \& Hertwich, 2008). Furthermore, shelter was also categorized causing GHG emission, but it has been stated that it can be controlled and diminished definitely with the help of inactive house technology (Sartori \& Hestnes, 2007).

\subsection{Contribution of the Study}

The main objective of this study was to ensure that ADU students are aware of their carbon emissions from daily activities. The study has contributed at raising awareness among students to change their life styles. Being students of Environmental sciences and Environmental Health \& Safety and responsible citizens of UAE, they should take serious steps to reduce carbon emission from their daily activities. Another point, which was considered during this study, was to teach the students how to estimate and calculate their carbon foot prints and how to minimize it.

Deploying carbon footprint provides a strong connection among the physical carbon cycle with the drivers of emissions. The standardization process at city and company level tends to portray that company and governments should start including the carbon footprint analysis during the process of decision making. On the international platform, the carbon footprint has the ability to address issues such as carbon leakage, border tax adjustments, and emission distributions between the countries that have increasingly received the attention from the policy makers. There exists an immense potential for the carbon foot print analysis that can be used at a variety of scales. The overall result of all students showed that the carbon footprint of ADU students before reduction is about $50 \%$ less than the UAE average. ADU students changed their daily activities to minimize their carbon emissions, so their carbon footprint was reduced to 12.22 tons/year which is $68 \%$ less than UAE average. The resulted value is very close to the industrial country average 11 tons/yr. More scientific research should be conducted on this issue, and new governmental policies and strategies should be implemented in UAE to protect the planet earth from adverse effects of global warming and climatic change. 


\subsection{Limitation of the Study}

The study has been restricted to calculate the carbon footprint of ADU students, studying environmental sciences and environmental health \& safety. A comparison was made among the student and the average carbon footprint of UAE. The study was only limited to the student's activities, which contributed to the highest carbon emission per year. Future studies must focus on the carbon footprint on account of waste produced, directly or indirectly, as the present study could not address this issue.

\section{Acknowledgement}

The authors are very thankful to all the associated personnel in any reference that contributed in/for the purpose of this research.

\section{References}

Ackerley, N., Sertkaya A., \& Lange, R. (2010). Food Transportation Safety: Characterizing Risks and Controls by Use of Expert Opinion. Food Protection Trends, 30, 212-222

Acquaye, A., Genovese, A., Barrett, J., \& Lenny Koh, S. C. (2014). Benchmarking carbon emissions performance in supply chains. Supply Chain Management: An International Journal, 19(3), 306-321.

Badyda, A. J. (2010). Zagrożenia środowiskoweze strony transportu [Environmental impact of transport]. Nauka, 4, 115-125.

Bendickson, N. J. (2007). Transportation and food distribution security. TransActions, NAOSH Week 2007 (Special Edition): 15-17.

Benjaafar, S., Li, Y., \& Daskin, M. (2013). Carbon footprint and the management of supply chains: Insights from simple models. IEEE Transactions on Automation Science and Engineering, 10, 99-116.

Brand, C., Goodman, A., Rutter, H., Song, Y., \& Ogilvie, D. (2013). Associations of individual, household and environmental characteristics with carbon dioxide emissions from motorised passenger travel. Appl Energ, 104, 158-169.

Buendia, L., Miwa, K., Ngara, T., \& Tanabe, K. (2006). IPCC Guidelines for National Greenhouse Gas Inventories. Prepared by the National Greenhouse Gas Inventories Programme. IGES, Hayama, Japan.

Carbon footprint. (2010, March).

Conolly, K. B., (2008). Conquering the Carbon Footprint, 10/08/2008.

Finkbeiner, M. (2009). Carbon footprinting-opportunities and threats. The International Journal of Life Cycle Assessment, 14(2), 91-94.

Hertwich, E. G., \& Peters, G. P. (2009). Carbon footprint of nations: A global, trade-linked analysis. Environ Sci Technol, 43, 6414-6420.

Herzog, T. (2009). World greenhouse gas emissions in 2005. World Resources Institute.

Integrating waste and renewable energy to reduce the carbon footprint of locally integrated energy sectors. (2008, Octobrt).

Konicyzni, D. (2013). Using carbon foot print to evaluate environmental issues of food transportations. Log forum, 1-9.

Lee, K. H. (2011). Integrating carbon footprint into supply chain management: the case of Hyundai Motor Company (HMC) in the automobile industry. Journal of Cleaner Production, 19(11), 1216-1223. http://dx.doi.org/10.1016/j.jclepro.2011.03.010

Li, X., Tan, H., \& Rackes, A. (2015). Carbon footprint analysis of student behavior for a sustainable university

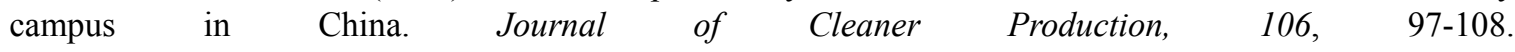
http://dx.doi.org/10.1016/j.jclepro.2014.11.084

Muthu, S. S. (Ed.). (2015). Handbook of life cycle assessment (LCA) of textiles and clothing. Woodhead Publishing.

Peters, G. P., \& Hertwich, E. G. (2008). $\mathrm{CO}_{2}$ embodied in international trade with implications for global climate policy. Environ Sci Technol, 42, 1401-1407.

Pimetel, D. (2006). Impacts of Organic Farming on the Efficiency of Energy Use in Agriculture, Ed. The Organic Center, Cornell University, Ithaca, USA. 
Print, C. F. (2013). Carbon foot print. Time for change.

Sartori, I., \& Hestnes, A. G. (2007). Energy use in the life cycle of conventional and low-energy buildings: A review article. Energ Buildings, 39, 249-257. http://dx.doi.org/10.1016/j.enbuild.2006.07.001

Sivaram, P. M. A. (2015). Carbon Footprint Analysis of an Educational Institution. Applied Mechanics and Materials, 1-6.

Sources of Greenhouse Gas Emissions. (2015, April 11).

Spooner, A. (2012). Environmental Science for Dummies. New Jersey: John Wiley \& Sons. Inc.

Terry, B. (2015). Carbon foot print. R

Weber, C. L., \& Matthews, H. S. (2008). Quantifying the global and distributional aspects of American household carbon footprint. Ecol Econ, 66, 379-391. http://dx.doi.org/10.1016/j.ecolecon.2007.09.021

Wiedmann, T. O., Schandl, H., Lenzen, M., Moran, D., Suh, S., West, J., \& Kanemoto, K. (2015). The material footprint of nations. Natl Acad Sci, 112, 6271-6276.

\section{Copyrights}

Copyright for this article is retained by the author(s), with first publication rights granted to the journal.

This is an open-access article distributed under the terms and conditions of the Creative Commons Attribution license (http://creativecommons.org/licenses/by/4.0/). 